\title{
A NEW APPROACH FOR EVALUATING THE RANKINE CYCLE THROUGH ENTROPY GENERATION
}

\author{
A. Sinan Karakurt ${ }^{1, *}$, Umit Gunes ${ }^{1}$
}

\begin{abstract}
Increasing oil prices, the growing demand for energy, the adoption of new regulations for greenhouse gases and other harmful particulate emissions, as well as political instabilities and crises have necessitated the design of more efficient and environmentally-friendly plants. This paper presents a useful combination of mean cycle irreversibility (MCI) for thermodynamically optimizing the Rankine cycle using the MCI as the currently proposed criterion. The thermal irreversibilities and physical size of a system are evaluated together using the criterion that aims to minimize the ratio of the thermal irreversibilities or exergy destruction to a specified size that is characterized as the difference between the maximum and the minimum specific volumes of the cycle. The analyses consider the effects of different boiler-outlet or turbine-inlet pressures and temperatures, different condenser pressures, and different isentropic efficiencies on cycle performance. The results show that increasing the inlet temperature for a constant turbine-inlet pressure increases the MCI and increasing the turbine-inlet pressure at a constant inlet temperature decreases the MCI. With boiler pressure at $500 \mathrm{kPa}$, the boiler temperature increases from $500 \mathrm{~K}$ to $600 \mathrm{~K}$, the MCI value increases nearly seven-fold, and thermal efficiency increases from $14 \%$ to nearly $16 \%$. Also, the results show that the criterion gives more beneficial information to designers and engineers in terms of exergy destruction for designing more environmentally friendly and smaller thermal systems.
\end{abstract}

\section{Keywords: Rankine Cycle, Entropy Generation, Exergy Density}

\section{INTRODUCTION}

The increases in global-energy demand, material and fuel prices, and restrictive emissions regulations has necessitated the design of more efficient, environmentally-friendly, and more compact thermal systems. In order to develop innovative systems, using all kinds of energy sources with smaller system more ecologically is important. In this context, using low-grade heat sources or recovering waste heat through different types of thermal applications, such as direct energy conversion or the Rankine cycle, which are well-known and widelyused technologies for energy production, is very important. Within this scope, low-pressure steam-turbine thermal systems have many application areas for energy production, from recovering the waste-heat energy of marine engines, diesel trucks, and industrial plants to renewable energy sources from solar, geothermal, or biogas or the fossil fuels used in small thermal plants.

From the first steam engine to current technology, even throughout the history of thermodynamics, many technological achievements have been done in the names of increasing thermal efficiency and decreasing environmental destruction with smaller developed systems. In this regard entropy generation minimization (EGM), also known as "thermodynamic optimization" or "finite time thermodynamics," has great importance in thermal system analyses. We should note that studies became crucial starting with Bejan's [1,2]. EGM combines the fundamental principles of thermodynamics, heat transfer, and fluid mechanics. Also, Bejan illustrated how EGM can be applied to real devices.

Plenty of studies are found to have focused on EGM, such as Martins' [3] showing entropy generation in spark ignition engines and Haseli's [4] analyzing the thermal performance of heat engines (i.e., Otto, diesel, and Brayton cycles). Tchanche et al. [5] presented applications for the the organic Rankine cycle (ORC) and analyzed their usage with solar energy, geothermal energy, biomass products, surface seawater, and waste heat from various thermal processes as a heat source. In addition to types of heat sources, Xiaojun et al. [6] developed mathematical models for investigating ORC's feasibility for power systems working under conditions with 150$350^{\circ} \mathrm{C}$ heat sources. They indicated ORC to have the highest thermal performance in cases with $150-210^{\circ} \mathrm{C}$ heat sources; steam-ORCs (S-ORCs) have higher thermal performance than steam Rankine cycles (SRCs) and ORC 
systems in cases with $210-350^{\circ} \mathrm{C}$ heat sources. Andreasen et al. [7] also compared SRCs and ORCs for wasteheat recovery in marine engines. Their results show that, while ORCs have higher thermal performance at lower engine loads, SRCs have higher thermal performance at higher engine loads.

Analyzing thermal efficiency and size has been very important because thermal performance is insufficient for a feasibility study; the system size also needs to be known. In this regard, Sahin et al. [8] defined a new expression for power density as the ratio of power to the maximum specific volume in the cycle. Therefore, they were able to include the effects of engine size in their thermal analysis. Ust et al. [9] indicated the ecological coefficient of performance (ECOP) to be the ratio of power output to the rate of loss of availability. They did the analysis using the ECOP objective function for generalized irreversible Carnot heat engines as well as the irreversible Brayton heat engine with variable-temperature thermal reservoirs using the ECOP objective function [10]. Yeginer et al. [11] presented their analysis of different thermodynamic cycles, such as Brayton, Rankine, and Otto. Chen et al. [12] gathered power, efficiency, entropy-generation rate, and ecological optimization studies and analyzed universal heat-engine cycles such as the Diesel, Otto, Brayton, Atkinson, dual, and Miller cycles.

Karakurt and Sahin [13] have defined exergy density as the ratio of physical exergy to specific volume at a given point. Gunes et al. [14] also analyzed the effect of size on entropy generation for different types of waste-heat recovery boilers. The results show that, due to larger (dual pressure) boilers being more efficient, entropy generation is less per heat transfer compared to smaller (single pressure) boilers.

Although ECOP [9] defines the energy production for unit exergy destruction or irreversibilities and SGen [1] defines the irreversibilities of the system, there is a lack of information about the relationship between exergy destruction and volume. The main objective of this study is to evaluate both exergy destruction and the dimensions of the thermal system together. The specific objective of this study is to analyze a low-grade Rankine power cycle using the proposed criterion of mean cycle irreversibility (MCI) and other performance criteria (ECOP, $s_{\mathrm{Gen}}$ and $\eta_{\mathrm{th}}$ ) for different boiler temperatures, boiler pressures, condenser pressures, and isentropic efficiencies. The main objective of this study is to evaluate together both the exergy destruction and the dimensions of the thermal system. The specific objective of this study is to analyze a low-grade Rankine power cycle using the proposed criterion (MCI) and other performance criteria (ECOP, $s_{\mathrm{Gen}}$ and $\eta_{\mathrm{th}}$ ) for different boiler temperatures, boiler pressures, condenser pressures, and isentropic efficiencies.

\section{THERMODYNAMIC MODEL}

The analyses have modeled the simple Rankine cycle's four processes using Engineering Equation Solver (EES) [15]. The dead state/ $\eta$ conditions have been assumed as $298 \mathrm{~K}$ and $10 \mathrm{kPa}$ for the Rankine cycle, the boiler temperature as $500 \mathrm{~K}$, boiler pressure as $1000 \mathrm{kPa}$, and condenser pressure as $50 \mathrm{kPa}$; pressure losses are neglected in pipes and heat exchangers, working fluid is non-compressible, and the isentropic efficiency of the pump and turbine is 0.9 . The values for the state properties $(T, P, v, h, s, e x)$ of cycle points can be obtained from the property tables, and the exergy density $\left(\rho_{\mathrm{Ex}}\right)$ [16] values can be calculated as the ratio of specific exergy to the specific volume at a point. The specific exergy values of state points can be calculated as in Equation 1 while neglecting the potential and kinetic exergies; and heat transfers $\left(q_{H}\right.$ and $\left.q_{L}\right)$ are calculated by assuming the specific enthalpy difference at the boiler and condenser units as from Equations 2 and 3. Thermal efficiency of the system can be calculated using Equation 4,

$$
\begin{gathered}
e x_{m}=h_{m}-h_{0}-T_{0} \cdot\left(\mathrm{s}_{m}-s_{0}\right) \\
q_{H}=h_{3}-h_{2} \\
q_{L}=h_{4}-h_{1} \\
\eta_{t h}=\frac{q_{H}-q_{L}}{q_{H}}
\end{gathered}
$$

where $m$-values between 1 and 4 refer to cycle points and an $m$-value of $O$ is the dead state conditions; $h$ is the specific enthalpy in the $\mathrm{kJ} / \mathrm{kg}$ unit, and $s$ is the specific entropy in the $\mathrm{kJ} /(\mathrm{kg} . \mathrm{K})$ unit, which are specifiable from the property tables of water. 
Entropy generation is defined in Equation 5 as a comparative tool for combining real and finite times and finite size systems using the most basic concepts of heat transfer, fluid mechanics, and thermodynamics [1]. Total exergy destruction of the system can be calculated using Equation 6.

$$
\begin{gathered}
s_{G e n}=\left(-\frac{q_{H}}{T_{H}}+\frac{q_{L}}{T_{L}}\right) \\
E X D_{T o t}=T_{0} s_{G e n}
\end{gathered}
$$

where $q_{H}$, (hot side of the heat transfer) is assumed to be equal to the heat addition to the cycle and also $T_{H}$ (hotside source temperature) is equal to the maximum temperature of the cycle, $T_{3}$. The variable $q_{L}$ (cold-side heat transfer) is assumed to be equal to the heat outlet from the cycle, and $T_{L}$ (cold-side source temperature) is equal to the minimum temperature of the cycle $\left(T_{4}\right)$ such that no temperature difference exists between the heat sources and heat machine. $T_{0}$ refers to the ambient/dead-state temperature.

The ecological coefficient of performance $(E C O P)$ is defined in Equation 7 as the ratio of the net specific work to exergy destruction [17].

$$
E C O P=\frac{W_{N e t}}{E X D_{T o t}}
$$

Based on exergy density $\left(\rho_{E x}\right)$ [16], Equation 8 defines the new ecological criterion of mean cycle irreversibility $(M C I)$ as the ratio of the cycle's exergy-destruction value to the difference between the cycle's maximum and the minimum specific volumes.

$$
M C I=\frac{E x D_{T o t}}{V_{\max }-V_{\min }}
$$

where $v_{\max }$ refers to the cycle's maximum specific volume and $v_{\min }$ refers to its minimum specific volume obtainable from the thermodynamic properties table; therefore, the difference gives an approximation of the cycle's volume for net energy production and exergy destruction.

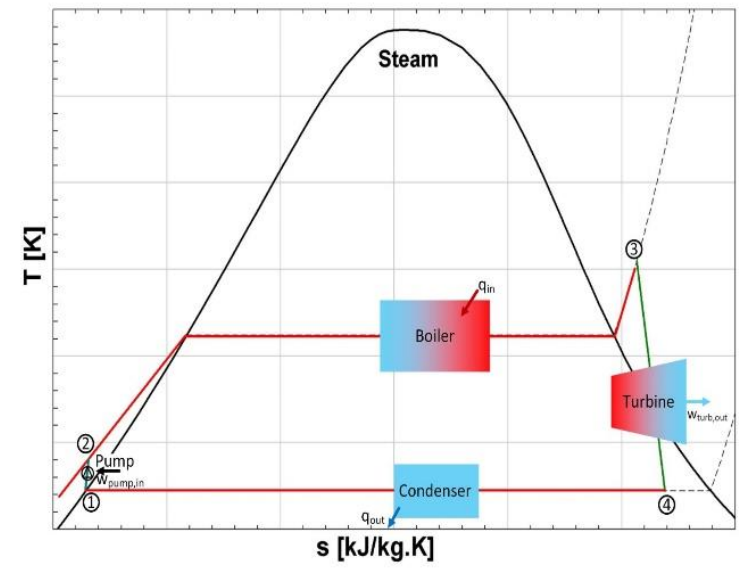

(a)

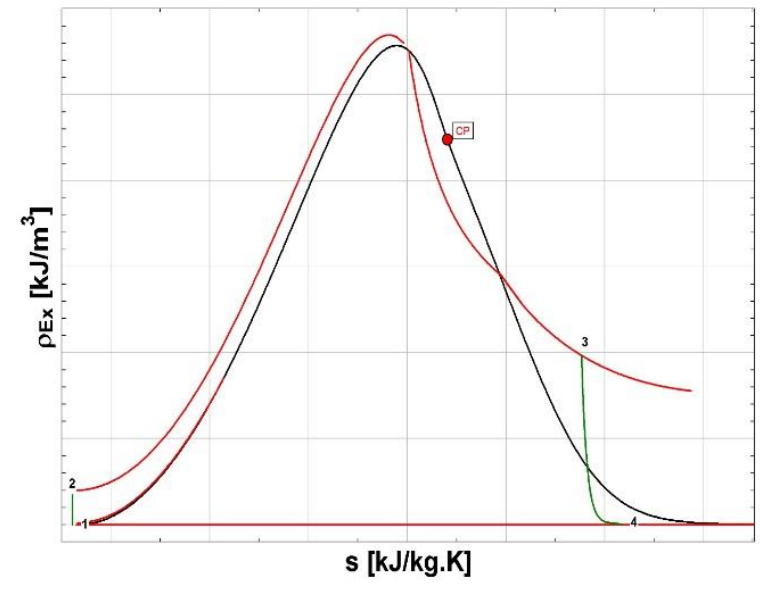

(b)

Figure 1. Simple ideal Rankine cycle, (a) $T-s$, (b) $\rho_{E x}-s$ diagram

Schematic of the simple ideal Rankine cycle and diagrams of temperature-specific entropy $(T-s)$ and the exergy density-specific entropy $\left(\rho_{E x}-s\right)$ are given in Figure 1. In this context, the exergy density diagram gives an approximation for availability and size at points in the cycle [16].

\section{RESULTS AND DISCUSSION}

The system's irreversibilities or exergy destructions and physical size have both been evaluated together through the proposed criterion with the aim of minimizing the value of exergy destructions at a specified size or 
volume of the cycle. This criterion can be used for designing and analyzing real thermal systems and processes for given conditions and for examining the impact of system-design parameters on performance. The analyses have been based on the parametric variations of boiler temperature, boiler pressure, condenser pressure, and isentropic efficiency. With respect to initial conditions and assumptions, the calculated and obtained magnitudes for pressure, temperature, specific volume, specific entropy, specific enthalpy, specific exergy, and exergy density of the state points in the Rankine cycle are given in Table 1.

Table 1. Thermophysical Properties of the Rankine Cycle

\begin{tabular}{|l|l|l|l|l|l|l|l|}
\hline $\boldsymbol{m}$ & $\boldsymbol{P}$ & $\boldsymbol{T}$ & $\boldsymbol{v}$ & $\boldsymbol{s}$ & $\boldsymbol{H}$ & $\boldsymbol{e x}$ & $\boldsymbol{\rho}_{\boldsymbol{E x}}$ \\
\hline [units] & {$[\mathrm{kPa}]$} & {$[\mathrm{K}]$} & {$\left[\mathrm{m}^{3} / \mathrm{kg}\right]$} & {$[\mathrm{kJ} / \mathrm{kg} . \mathrm{K}]$} & {$[\mathrm{kJ} / \mathrm{kg}]$} & {$[\mathrm{kJ} / \mathrm{kg}]$} & {$\left[\mathrm{kJ} / \mathrm{m}^{3}\right]$} \\
\hline 1 & 50 & 354.5 & 0.00103 & 1.0912 & 340.5 & 19.96 & 19381 \\
\hline 2 & 1000 & 354.5 & 0.00103 & 1.0912 & 341.5 & 20.94 & 20331 \\
\hline 3 & 1000 & 500 & 0.2206 & 6.825 & 2891 & 862 & 3907 \\
\hline 4 & 50 & 354.5 & 2.93 & 6.9712 & 2425 & 352 & 120.1 \\
\hline
\end{tabular}

Isentropic efficiency is a very important parameter affecting turbomachinery system performance. It shows the effect of turbine or pump loses in the ideal case. The analyses have used three different isentropic efficiencies $(1.0,0.90$, and 0.80). While keeping the other design parameters constant, the effects of isentropic efficiency on the performance criteria can be seen in Fig. 2. The finding is clearly obtained from the figure that when isentropic efficiency decreases, irreversibilities or exergy destructions and MCI increase while thermal efficiency and ECOP decrease. However, achieving higher isentropic efficiencies also incredibly increases the initial costs.

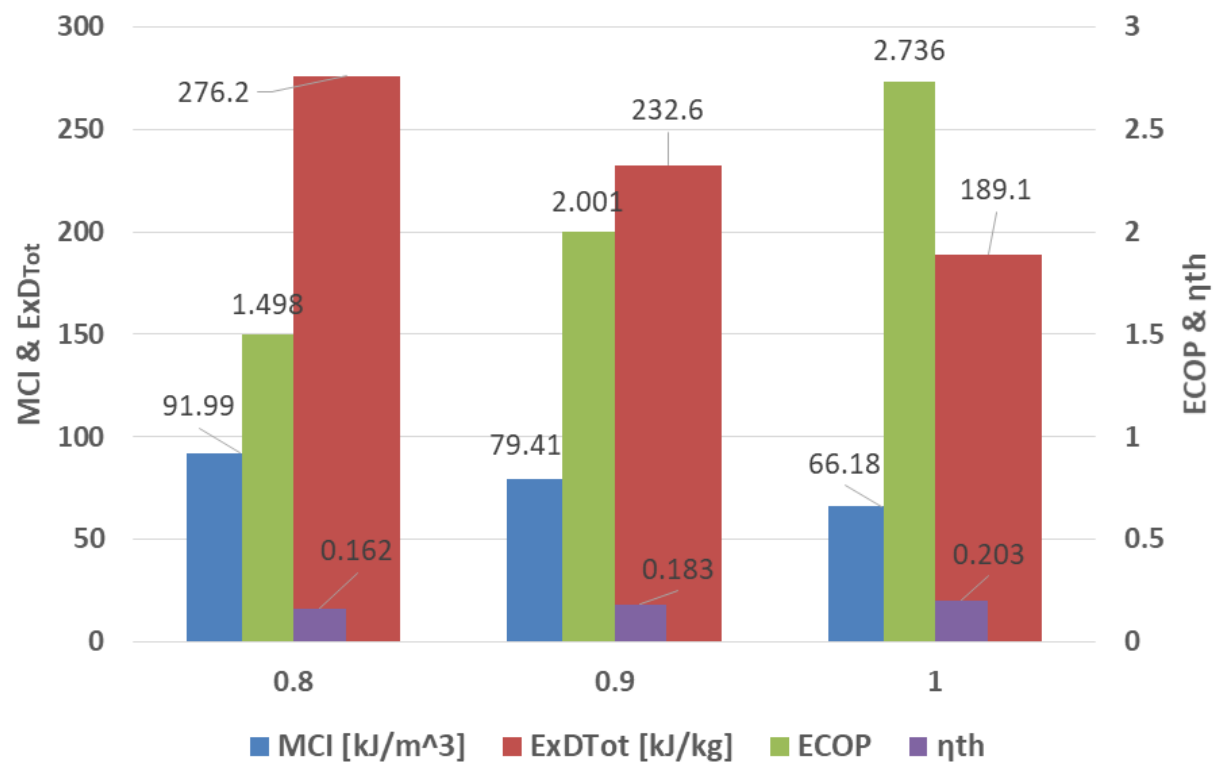

Figure 2. The effects of isentropic efficiency on the performance criteria

Condenser pressure is another important parameter for performance outputs and system size in the Rankine power cycle. As such, choosing the best working conditions is very important for an efficient, ecofriendly, and more compact system. While keeping all other parameters constant, the effects of different condenser pressures $(50,75$, and $100 \mathrm{kPa})$ on performance output are given in Figure 3. Exergy destruction, thermal efficiency, and ECOP values decrease and the MCI value increases with increases in condenser pressure. This is because higher condenser pressures mean the system will have less energy and lower specific volumes. 
Journal of Thermal Engineering, Research Article, Vol. 5, No. 6, Special Issue 10, pp. 141-148, December, 2019

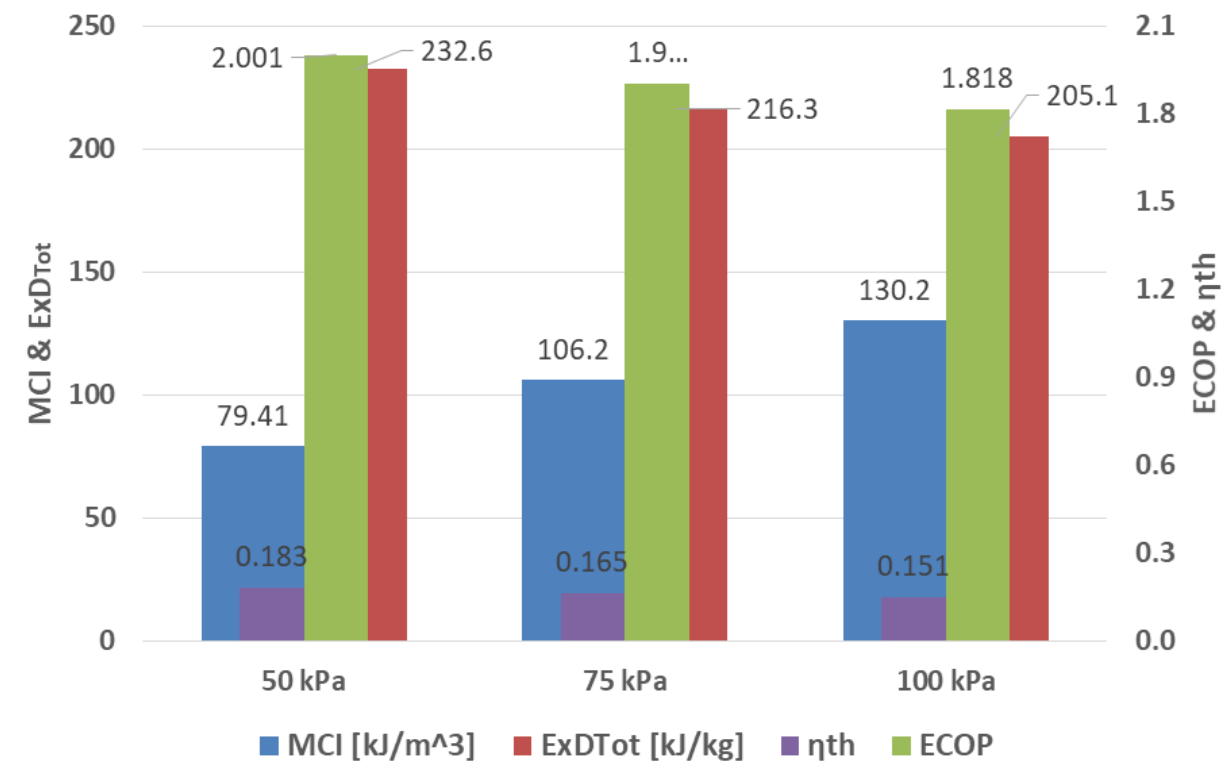

Figure 3. The effects of condenser pressure on the performance criteria

Boiler pressure and temperature, which highly relate to the material properties, component costs, and energy output, are effective parameters in the Rankine power cycle. Because of their importance, the combination of these two parameters is very effective for thermal systems. Assuming condenser pressure and isentropic efficiency to be constant, the effects of increasing boiler pressure from $500 \mathrm{kPa}$ to $2000 \mathrm{kPa}$ for three different boiler temperatures $(500 \mathrm{~K}, 550 \mathrm{~K}$ and $600 \mathrm{~K}$ ) on performance output are given in Figure 4 . When boiler pressure increases at a constant boiler temperature and ECOP increases at various rates, MCI decreases linearly due to the decrease in exergy destruction and the volume difference being kept nearly constant.

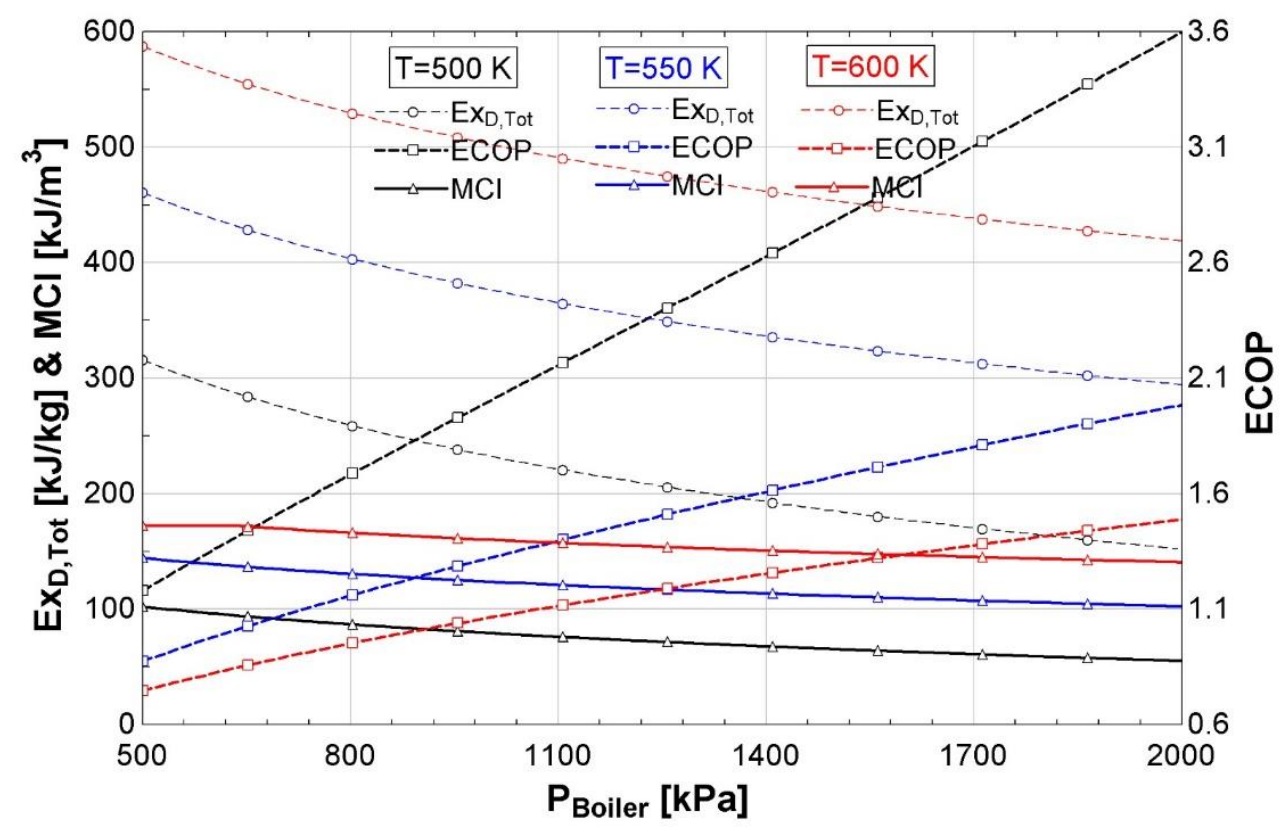

Figure 4. The effects of boiler pressure on MCI and $\eta_{\text {th }}$

When keeping condenser pressure and isentropic efficiency constant, the effects raising boiler temperature from $425 \mathrm{~K}$ to $575 \mathrm{~K}$ with respect to the saturation temperature at related pressure for four boiler pressures $(500 \mathrm{kPa}, 1000 \mathrm{kPa}, 1500 \mathrm{kPa}$, and $2000 \mathrm{kPa})$ on performance output are given in Fig. 5. When boiler temperature is increased at a constant boiler pressure, both exergy destruction and $\mathrm{MCI}$ increase but with a greater slope for the increment of exergy destruction. This is due to increases in temperature affecting exergy destruction more than increases in pressure. ECOP values exponentially decrease with increases in boiler 
temperature at constant boiler pressure; ECOP also increases with increases in pressure at constant boiler temperatures.

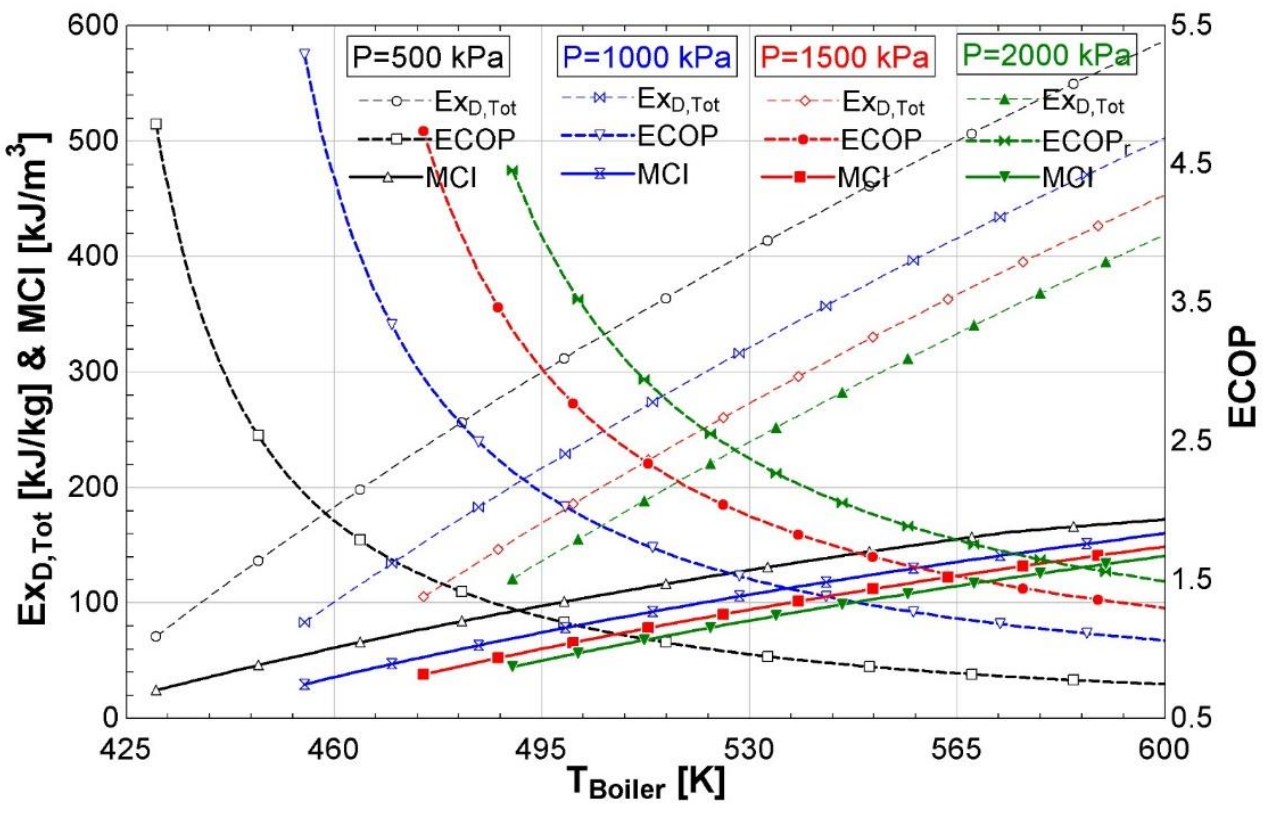

Figure 5. The effects of boiler temperature on MCI and $\eta_{\text {th }}$

The ecological performance map of the effects of boiler pressure and temperature on MCI and thermal efficiency is given in Figure 6. The straight lines refer to the boiler temperature shifting from $500 \mathrm{~K}$ to $600 \mathrm{~K}$ at a constant boiler pressure. The dotted lines refer to boiler pressure variations from $500 \mathrm{kPa} 2000 \mathrm{kPa}$ at a constant boiler temperature. The intersection of both design parameters gives us some information about the effects of the selected conditions: The first is how our system is efficient, and the second is the ecological dimension of our system. When the boiler temperature increases from $500 \mathrm{~K}$ to $600 \mathrm{~K}$ at a constant boiler pressure of $500 \mathrm{kPa}$, MCI increases nearly seven fold while thermal efficiency increases from $14 \%$ to nearly $16 \%$.

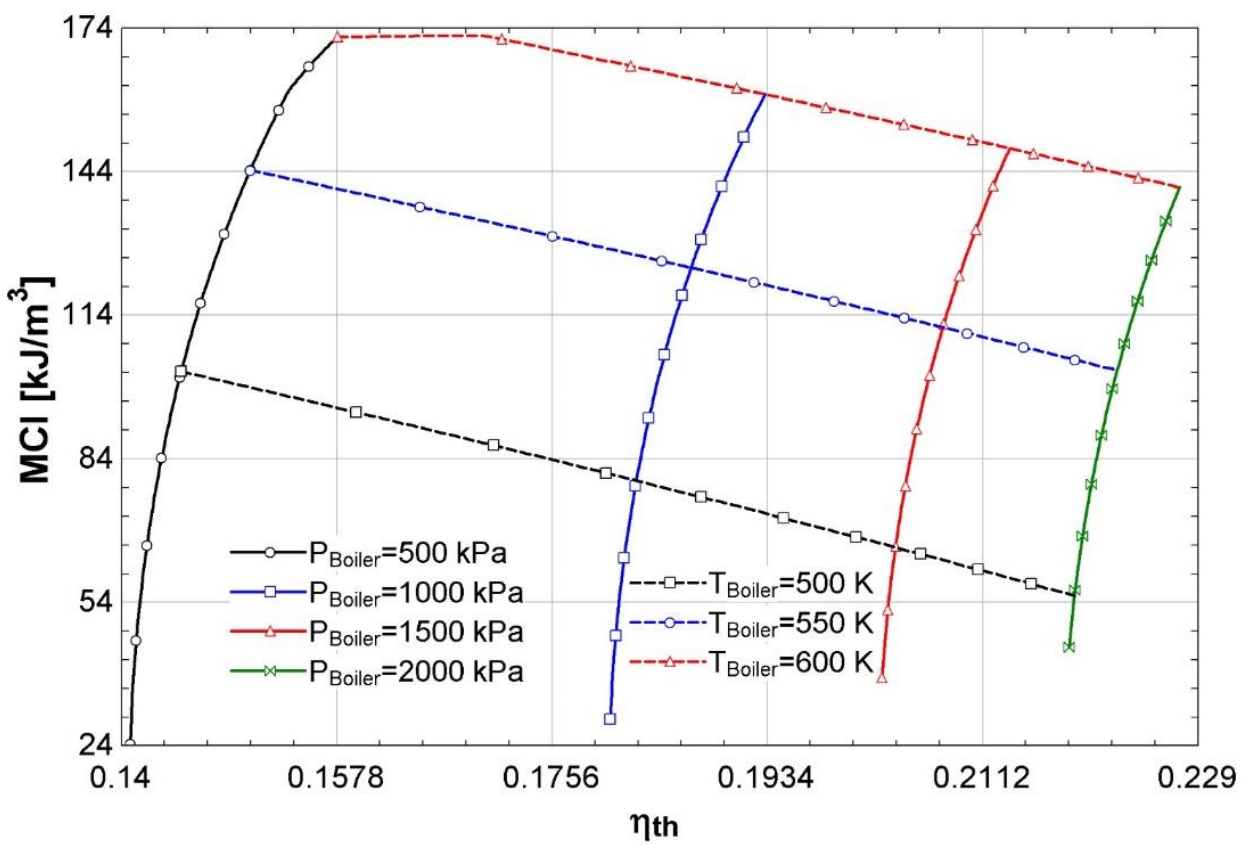

Figure 6. The effects of boiler pressure and boiler temperature on MCI and $\eta_{\text {th }}$

\section{CONCLUSION}

One of the inevitable consequences of the increases in energy demands and production is the increase in the disorder or entropy of our unique world and environment. Thus, developing more environmentally friendly 
systems is vitally important while developing the performance outputs of thermal systems. In addition to this, in an era where the latest technology is in our pocket, optimizing the dimensions of thermal systems is very important. In this context, the proposed criterion of MCI has been evaluated together with both exergy destruction and the dimensions of thermal systems; it has given a projection for designers and engineers about the ecological dimensions of a system. Develop this criterion to be more applicable and more realistic for all kinds of thermal system is expected.

\section{NOMENCLATURE}

$\begin{array}{ll}E x & \text { Specific exergy, } \mathrm{kJ} / \mathrm{kg} \\ E C O P & \text { Ecological Coefficient of Performance } \\ E G M & \text { Entropy Generation Minimization } \\ H & \text { Specific enthalpy, } \mathrm{kJ} / \mathrm{kg} \\ M C I & \text { Mean cycle irreversibility, } \mathrm{kJ} / \mathrm{m}^{3} \\ P & \text { Pressure, } \mathrm{kPa} \\ \text { ORC } & \text { Organic Rankine cycles } \\ q & \text { Heat transfer, } \mathrm{kJ} / \mathrm{kg} \\ s & \text { Specific entropy, } \mathrm{kJ} /(\mathrm{kg} . \mathrm{K}) \\ S-O R C & \text { Steam-Organic Rankine Cycle } \\ S R C & \text { Steam Rankine Cycle } \\ T & \text { Temperature, } \mathrm{K} \\ w & \text { Specific work, } \mathrm{kJ} / \mathrm{kg} \\ v & \text { Specific volume, } \mathrm{m}^{3} / \mathrm{kg} \\ 0 & \text { Dead state } \\ E & \text { Expansion } \\ E x & \text { Exergy } \\ G e n & \text { Generated } \\ H & \text { Hot temperature side } \\ i & \text { Isentropic } \\ L & \text { Low temperature side } \\ m & \text { State point } \\ m a x & \text { Maximum } \\ m i n & \text { Minimum } \\ N e t & \text { Net } \\ P & \text { Pumping } \\ t h & \text { Thermal } \\ \eta & \text { Efficiency } \\ & \end{array}$

\section{REFERENCES}

[1] Bejan, A. (1996). Entropy generation minimization: The new thermodynamics of finite-size devices and finite-time processes. J. Appl. Phys., 79(3), 1191-1218.

[2] Bejan, A. (2012). Entropy generation minimization, exergy analysis, and the constructal law," Arab. J. Sci. Eng., 38(2), 329-340.

[3] Martins, J. J. G., Ribeiro, B. S., \& Ion, V. (2009). Thermodynamic analysis of spark 1gnition engines using the entropy generation minimisation method. Int. J. Exergy, 6(1), 93.

[4] Haseli, Y. (2013). Performance of irreversible heat engines at minimum entropy generation. Appl. Math. Model., 37(23), 9810-9817.

[5] Tchanche, B. F., Lambrinos, G., Frangoudakis, A., \& Papadakis, G. (2011). Low-grade heat conversion into power using organic Rankine cycles - A review of various applications. Renew. Sustain. Energy Rev., 15(8), 3963-3979.

[6] Zhang, X., Wu, L., Wang, X., \& Ju, G. (2016). Comparative study of waste heat steam SRC, ORC, and SORC power generation systems in medium-low temperature. Appl. Therm. Eng., 106, 1427-1439.

[7] Andreasen, J., Meroni, A., \& Haglind, F. (2017). A comparison of organic and steam Rankine cycle power systems for waste heat recovery on large ships. Energies, 10(4), 547.

[8] Sahin, B., Kodal, A., \& Yavuz, H. (1995). Efficiency of a Joule-Brayton engine at maximum power density. J. Phys. Appl. Phys., 28(7), 1309. 
[9] Üst, Y., Sahin, B., \& Kodal, A. (2005). Ecological coefficient of performance (ECOP) optimization for generalized irreversible Carnot heat engines. J. Energy Inst., 78(3), 145-151.

[10] Ust, Y., Sogut, O. S., Sahin, B., \& Durmayaz, A. (2006). Ecological coefficient of performance (ECOP) optimization for an irreversible Brayton heat engine with variable-temperature thermal reservoirs," J. Energy Inst., 79(1), 47-52.

[11] Yeğiner, Y., Kenç, S., Özkol, I., \& Kömürgöz, G. (2013). ECOP-based comparative study of thermodynamic cycles. Appl. Mech. Mater., 390, 655-659.

[12] Chen, L., Zhang, W., \& Sun, F. (2007). Power, efficiency, entropy-generation rate and ecological optimization for a class of generalized urreversible universal heat-engine cycles. Appl. Energy, 84(5), 512-525.

[13] Karakurt, A. S., \& Sahin, B. (2019). A new method for the size and performance analyses and optimization of thermal systems: The exergy density. Sigma J. Eng. Nat. Sci., 37(2), 573-583.

[14] Gunes, U., Karakurt, A. S., \& Sahin, B. (2019). The effect of size on entropy generation for waste heat recovery boiler. Paper presented at The 32nd International Conference on Efficiency, Cost, Optimization, Simulation and Environmental Impact of Energy System (pp. 809-818). Wroclaw, Poland

[15] Klein, S. A., \& Alvarado, F. L. (2019). EES-engineering equation solver. F-Chart Software, 4406 Fox Bluff Rd., Middleton, WI.

[16] Karakurt, A. S. (2018). A new method for the size and performance optimization of thermal systems: The exergy density (unpublished doctoral dissertation). Yildiz Technical University, Istanbul Turkey.

[17] Üst, Y., Sahin, B., \& Kodal, A. (2005). Ecological coefficient of performance (ECOP) optimization for generalized irreversible Carnot heat engines. J. Energy Inst., 78(3), 145-151. 